American Journal of Applied Sciences 6 (7): 1396-1402, 2009

ISSN 1546-9239

(C) 2009 Science Publications

\title{
Finite Element Analysis of the Crack Propagation for Solid Materials
}

\author{
Miloud Souiyah, A. Muchtar, Abdulnaser Alshoaibi and A.K. Ariffin \\ Department of Mechanical and Materials Engineering, University Kebangsaan Malaysia, \\ 43600 UKM Bangi, Selangor, Malaysia
}

\begin{abstract}
Problem statement: The use of fracture mechanics techniques in the assessment of performance and reliability of structure is on increase and the prediction of crack propagation in structure play important part. The finite element method is widely used for the evaluation of SIF for various types of crack configurations. Source code program of two-dimensional finite element model had been developed, to demonstrate the capability and its limitations, in predicting the crack propagation trajectory and the SIF values under linear elastic fracture analysis. Approach: Two different geometries were used on this finite element model in order, to analyze the reliability of this program on the crack propagation in linear and nonlinear elastic fracture mechanics. These geometries were namely; a rectangular plate with crack emanating from square-hole and Double Edge Notched Plate (DENT). Where, both geometries are in tensile loading and under mode I conditions. In addition, the source code program of this model was written by FORTRAN language. Therefore, a Displacement Extrapolation Technique (DET) was employed particularly, to predict the crack propagations directions and to, calculate the Stress Intensity Factors (SIFs). Furthermore, the mesh for the finite elements was the unstructured type; generated using the advancing front method. And, the global $h$-type adaptive mesh was adopted based on the norm stress error estimator. While, the quarterpoint singular elements were uniformly generated around the crack tip in the form of a rosette. Moreover, make a comparison between this current study with other relevant and published research study. Results: The application of the source code program of 2-D finite element model showed a significant result on linear elastic fracture mechanics. Based on the findings of the two different geometries from the current study, the result showed a good agreement. And, it seems like very close compare to the other published results. Conclusion: A developed a source program of finite element model showed that is capable of demonstrating the SIF evaluation and the crack path direction satisfactorily. Therefore, the numerical finite element analysis with displacement extrapolation method, had been successfully employed for linear-elastic fracture mechanics problems.
\end{abstract}

Key words: Finite element, linear elastic fracture mechanics, adaptive refinement, stress intensity factors, finite element

\section{INTRODUCTION}

The use of fracture mechanics techniques in the assessment of performance and reliability of structure is on increase and the prediction of crack propagation in structure play important part. The finite element method is widely used for the evaluation of SIF for various types of crack configurations. Some methods based on point matching techniques with nodal displacements are widely used extrapolation techniques due to their simple applicability to various crack configurations. The Displacement Extrapolation Method (DEM) is an example of this type of technique. The stresses are computed from the displacement solutions that are the primary output of the FE programs. The energy-based methods like J-integral, energy release and the stiffness derivative methods are also used for the determination of $\mathrm{SIF}^{[1]}$. In addition, J-contour integration, the virtual crack extension and the strain energy release rate method. The main disadvantage of these methods is that the stress intensity factor components, $\mathrm{K}_{\mathrm{I}}$ and $\mathrm{K}_{\mathrm{II}}$ in mixed mode problems are either impossible or very difficult to be separated ${ }^{[2]}$.

A numerical analysis of cracks emanating from a circular hole and square hole in rectangular plate in tension was performed by means of the displacement discontinuity method with crack-tip elements ${ }^{[3]}$. Murakami $^{[4]}$ used the body force method to calculate

Corresponding Author: Miloud Souiyah, Department of Mechanical and Materials Engineering, University Kebangsaan Malaysia, 43600 UKM Bangi, Selangor, Malaysia 
their stress intensity factors, for a crack originating from a corner of a square hole in an infinite plate in tension. A mixed mode stress intensity factors of the bend specimen are computed by Finite Element Method (FEM) to determine the effects of different crack location and loading distances from the middle of the specimen $^{[5]}$. Laurencin ${ }^{[6]}$ employed a statistical analysis based on weakest link theory, to describe the brittle fracture induced at singularities in ceramic materials. Kutuka $^{[7]}$ developed two-dimensional finite element program, to determine SIF by using the displacement extrapolation method.

A new method based on the FE approach was developed for coupling the FEM and the BEM. This approach has been assessed by the evaluation of Stress Intensity Factors (SIF) using two examples of fracture mechanics, i.e., centre-cracked plate, (b) cracks emanating from a circular hole ${ }^{[8]}$. The prediction of fatigue crack path was applied on tensile specimen with holes. Using the values of $\mathrm{K}_{\mathrm{I}}$ and $\mathrm{K}_{\mathrm{II}}$ as well as the $\mathrm{T}$ stress were calculated, for the obtained curvilinear and reference crack path trajectories ${ }^{[9]}$. A finite element stress analysis program has been used to find values of the stress intensity factor, $K_{I}$, for radial cracks at the boundary of a hole in a finite plate under tension ${ }^{[10]}$. Finite element static stress intensity factor calculations for an annular crack around a spherical inclusion (void) are presented and compared with those from approximate analytical methods ${ }^{[11]}$. Newman ${ }^{[12]}$ made also analysis of cracks emanating from a circular hole both in infinite plate subjected to internal pressure and in rectangular plate in tension. Bowie ${ }^{[13]}$ gave solutions of a circular hole with a single edge crack and a pair of symmetrical edge cracks in a plate under tension. A numerical study has been considered ${ }^{[15]}$, in order to model the singularity near the crack-tip. The aim was to estimate numerically the values of SIFs using different techniques (classical finite element, enriched finite element and deformed finite element) for different specimens Central Notched (CN) and Single Edge Notched (SEN).

Objectives: To evaluate and validate the developed source code program of two-dimensional finite element model. Therefore, demonstrate the capability and the limitations of this model, in predicting the crack propagation trajectory and the SIF values under linear elastic fracture analysis. Furthermore, to make a comparison between this current studies with other relevant and published research work. The displacement extrapolation techniques with adaptive mesh finite element method are used, to determine the stress intensity factors. The source code program of this model is written by FORTRAN language.

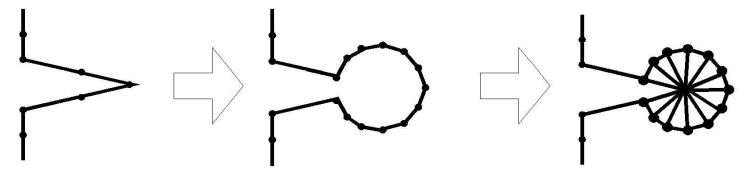

Fig. 1: The cut and patch procedure of generating singular elements around a crack tip

Two different geometries are considered in this work namely, a rectangular plate with cracks emanating from a square hole and Double Edge Notched Plate (DENT).

Stress intensity factor and crack propagation: The Stress Intensity Factor (SIF) is one the most important parameters in fracture mechanics analysis. It would, define sufficiently the stress field close to the crack tip and provide fundamental information of how the crack is going to propagate. In this study, the displacement extrapolation method was employed to, predict the crack propagation trajectory and to, calculate the stress intensity factors. In addition, for further details about this method ${ }^{[15]}$.

Mesh generation and adaptive refinement: In this study, the unstructured triangular mesh is automatically generated, by employing the advancing front method $^{[16]}$. The latest review of this method can be found in the previous research ${ }^{[17]}$. In order to represent the field singularity correctly at the crack tip, the singular elements have to be constructed. In our implementation, these special elements as shown in Fig. 1 are generated separately from the conventional ones. The singular elements have to be constructed, in order to get a proper field of singularity around the crack tip. An impressive discussion on the adaptive mesh generators was stated, by a group of research $^{[14,18-20]}$. The number of elements depends on the distributed nodes around the crack tip, which can be set by the user as shown in Fig. 1. Here the natural triangular quarter point elements are used instead of the collapse quadrilateral element ${ }^{[21]}$.

\section{MATERIALS AND METHODS}

Finite element method in fracture mechanics: Various numerical methods have been used to derive SIF such as Finite Difference Method (FDM), Finite Element Method (FEM) and Boundary Element Method (BEM). Among them, FEM has been widely employed for the solution of both fracture problems linear elastic and elasto-plastic. A typical and practical point matching technique, called Displacement Extrapolation Method (DEM) is chosen for the numerical analysis 
method. To determine the SIFs of the two well-known geometries, i.e., a rectangular plate with crack emanating from circular hole and Double Edge Notched Plate (DENT).

\section{RESULTS AND DISCUSSION}

Rectangular plate with crack emanating from square-hole in tensile loading: The geometry was imposed by plane strain condition and edge load $(\sigma)$ applied under mode I loading condition. The squarehole in rectangular plate together with the final adaptive mesh is shown in Fig. 2.

For this problem, the present study of crack emanating from a square hole in rectangular plate in tension is compared and validated, with a numerical solutions of $\mathrm{Yan}^{[3]}$. Taking in consideration the specimen parameters respectively, the ratio of $(\mathrm{a} / \mathrm{W})$ with various values of the initial crack length $(\mathrm{a} / \mathrm{c})$ together with range values of the height per width $(\mathrm{H} / \mathrm{W})$. The following cases are:


(a)
The SIFs (denoted by F) were normalized by $\sigma \sqrt{\pi \mathrm{a}}$. Therefore, the comparison results were illustrated in Table 1-3, of the current study with numerical solution of $\mathrm{Yan}^{[3]}$, for the ratio values of initial crack length per width $(\mathrm{a} / \mathrm{W}=0.2,0.4$ and 0.7$)$ respectively. It's found that the results, that obtained by FEM are in very good agreement with those results of a numerical solution (BEM).

The predictions of the crack propagation trajectories are considered on crack emanating from circular hole of rectangular plate. Figure 3 shows, the maximum principal stress distribution for the final step of the crack propagation. From Fig. 3 also, it seems obviously that, the stresses distribution is symmetric and the higher stress is concentrated at the crack tip because of the load effect. Therefore, four steps of the crack trajectories are shown in Fig. 4, which propagated as it was predicted straight forward from the both crack tips. Clearly, the results show that, the crack propagated gradually to the expected path under mode I loading condition. Furthermore, in this current study, we have come out with more results than the previous relevant studies in terms of, the crack propagation trajectory and the maximum principal stress.

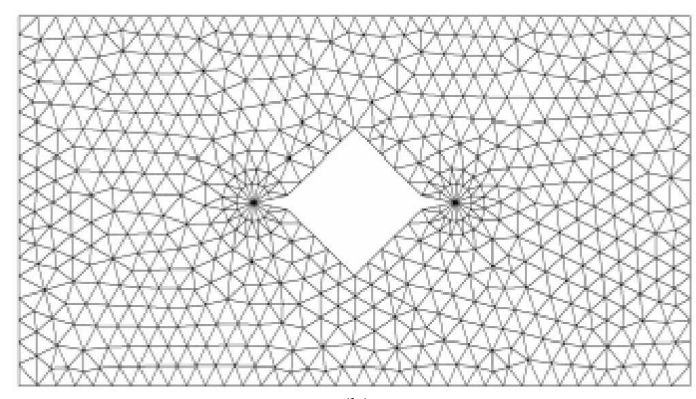

(b)

Fig. 2: The square-hole in rectangular plate (a): Specimen dimension; (b): Final adaptive mesh

Table 1: Shows the comparison of the normalized SIFs of the current study with those obtained by $\mathrm{Yan}^{[3]}(\mathrm{a} / \mathrm{W}=0.2)$

\begin{tabular}{|c|c|c|c|c|c|c|c|}
\hline \multicolumn{4}{|c|}{ Yan 2007} & \multicolumn{4}{|c|}{ Present study } \\
\hline \multirow[b]{2}{*}{$a / c$} & \multicolumn{3}{|l|}{$\mathrm{H} / \mathrm{W}$} & \multirow[b]{2}{*}{$a / c$} & \multicolumn{3}{|l|}{$\mathrm{H} / \mathrm{W}$} \\
\hline & 0.5 & 0.8 & 1 & & 0.5 & 0.8 & 1 \\
\hline 1.02 & 1.2576 & 1.1422 & 1.1054 & 1.02 & 1.2332 & 1.1226 & 1.1001 \\
\hline 1.04 & 1.2882 & 1.1698 & 1.1324 & 1.04 & 1.2710 & 1.1301 & 1.1122 \\
\hline 1.06 & 1.3020 & 1.1823 & 1.1448 & 1.06 & 1.2894 & 1.1552 & 1.1252 \\
\hline 1.08 & 1.3086 & 1.1883 & 1.1505 & 1.08 & 1.2998 & 1.1561 & 1.1385 \\
\hline 1.10 & 1.3124 & 1.1917 & 1.1541 & 1.10 & 1.3097 & 1.1634 & 1.1396 \\
\hline 1.15 & 1.3140 & 1.1931 & 1.1558 & 1.15 & 1.305 & 1.1689 & 1.1477 \\
\hline 1.20 & 1.3108 & 1.1902 & 1.1533 & 1.20 & 1.3869 & 1.1878 & 1.1422 \\
\hline 1.50 & 1.2779 & 1.1626 & 1.1276 & 1.50 & 1.2589 & 1.1536 & 1.1188 \\
\hline 2.00 & 1.2361 & 1.1287 & 1.0963 & 2.00 & 1.2199 & 1.1189 & 1.0779 \\
\hline
\end{tabular}


Am. J. Applied Sci., 6 (7): 1396-1402, 2009

Table 2: Shows the comparison of the normalized SIFs of the current study with those obtained by $\mathrm{Yan}^{[3]}(\mathrm{a} / \mathrm{W}=0.4)$

\begin{tabular}{|c|c|c|c|c|c|c|c|}
\hline \multicolumn{4}{|c|}{$\mathrm{Yan}^{[3]}$} & \multicolumn{4}{|c|}{ Present study } \\
\hline \multirow[b]{2}{*}{$\mathrm{a} / \mathrm{c}$} & \multicolumn{3}{|l|}{$\mathrm{H} / \mathrm{W}$} & \multirow[b]{2}{*}{$\mathrm{a} / \mathrm{c}$} & \multicolumn{3}{|l|}{$\mathrm{H} / \mathrm{W}$} \\
\hline & 0.5 & 0.7 & 1.5 & & 0.5 & 0.7 & 1.5 \\
\hline$\overline{1.02}$ & 2.0390 & 1.7381 & 1.2272 & 1.02 & 2.0030 & 1.7198 & 1.2122 \\
\hline 1.04 & 2.0880 & 1.7743 & 1.2554 & 1.04 & 2.0450 & 1.7341 & 1.2336 \\
\hline 1.06 & 2.1096 & 1.7877 & 1.2670 & 1.06 & 2.1038 & 1.7562 & 1.2380 \\
\hline 1.08 & 2.1192 & 1.7914 & 1.2715 & 1.08 & 2.1124 & 1.7755 & 1.2557 \\
\hline 1.10 & 2.1236 & 1.7925 & 1.2737 & 1.10 & 2.1998 & 1.7788 & 1.2581 \\
\hline 1.15 & 2.1187 & 1.7818 & 1.2718 & 1.15 & 2.1139 & 1.7677 & 1.2575 \\
\hline 1.20 & 2.1026 & 1.7652 & 1.2664 & 1.20 & 2.1100 & 1.7465 & 1.2497 \\
\hline 1.50 & 2.0037 & 1.6717 & 1.2245 & 1.50 & 2.0610 & 1.6454 & 1.2045 \\
\hline 2.00 & 1.8676 & 1.5656 & 1.1821 & 2.00 & 1.8398 & 1.5333 & 1.1726 \\
\hline
\end{tabular}

Table 3: Shows the comparison of the normalized SIFs of the current study with those obtained by $\mathrm{Yan}^{[3]}(\mathrm{a} / \mathrm{W}=0.7)$

\begin{tabular}{|c|c|c|c|c|c|c|c|}
\hline \multicolumn{4}{|c|}{$\operatorname{Yan}^{[3]}$} & \multicolumn{4}{|c|}{ Present study } \\
\hline \multirow[b]{2}{*}{$a / c$} & \multicolumn{3}{|l|}{$\mathrm{H} / \mathrm{W}$} & \multirow[b]{2}{*}{$a / c$} & \multicolumn{3}{|l|}{$\mathrm{H} / \mathrm{W}$} \\
\hline & 0.7 & 0.9 & 2 & & 0.7 & 0.9 & 2 \\
\hline 1.02 & 5.6584 & 4.1905 & 1.8099 & 1.02 & 5.6381 & 4.1700 & 1.8015 \\
\hline 1.04 & 5.7593 & 4.1912 & 1.8389 & 1.04 & 5.7211 & 4.1609 & 1.8103 \\
\hline 1.06 & 5.7835 & 4.1409 & 1.8465 & 1.06 & 5.7621 & 4.1212 & 1.7979 \\
\hline 1.08 & 5.7478 & 4.0607 & 1.8433 & 1.08 & 5.6989 & 4.0511 & 1.7879 \\
\hline 1.10 & 5.7166 & 3.9870 & 1.8393 & 1.10 & 5.6977 & 3.9550 & 1.7969 \\
\hline 1.15 & 5.5369 & 3.7750 & 1.8200 & 1.15 & 5.4998 & 3.7461 & 1.7770 \\
\hline 1.20 & 5.3084 & 3.5687 & 1.7990 & 1.20 & 5.3001 & 3.5498 & 1.700 \\
\hline 1.50 & 4.2996 & 2.8434 & 1.6945 & 1.50 & 4.2123 & 2.9001 & 1.6655 \\
\hline 2.00 & 3.2969 & 2.3218 & 1.6091 & 2.00 & 3.2779 & 2.2879 & 1.6001 \\
\hline
\end{tabular}

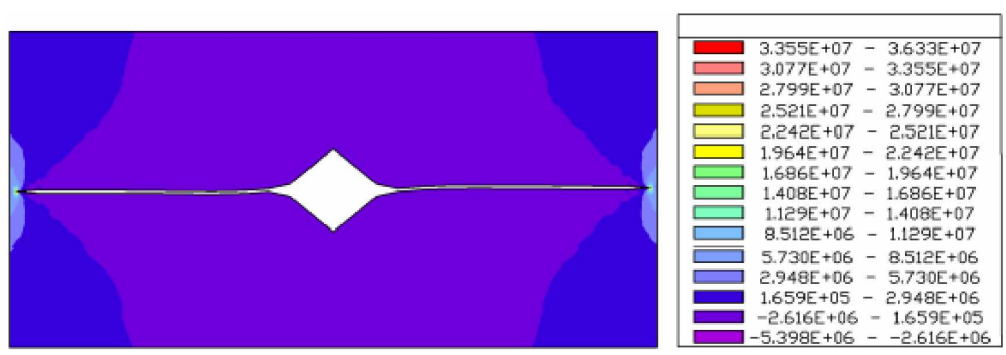

Fig. 3: Maximum principal stress distribution in rectangular plate with crack emanating from square hole

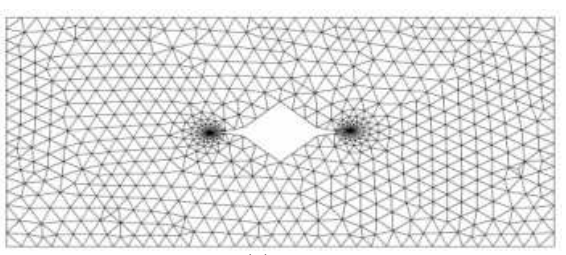

(a)

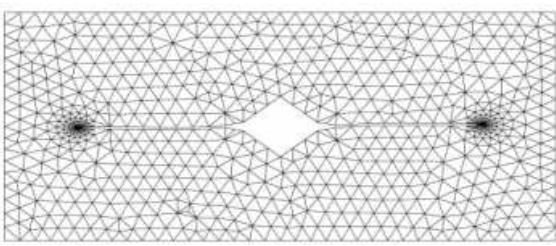

(c)

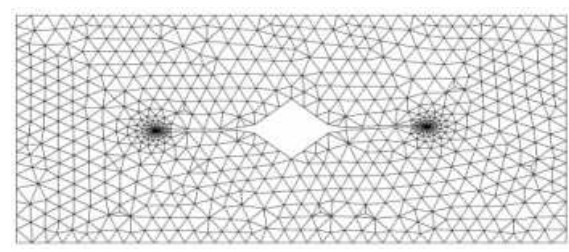

(b)

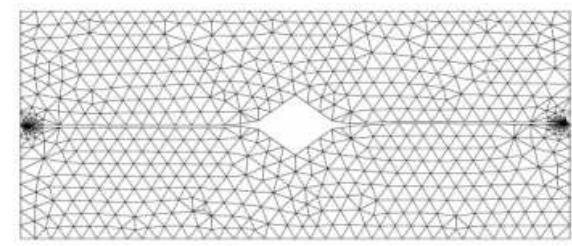

(d)

Fig. 4: Four steps of crack propagation trajectories for a crack emanating from square hole of rectangular plate 

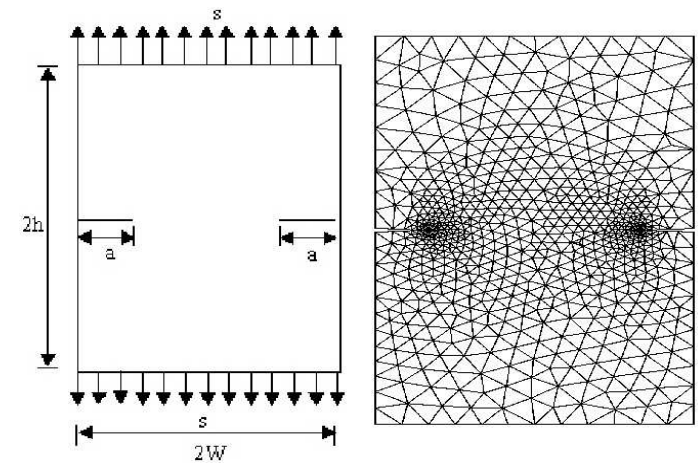

Fig. 5: Double edge notched plate (a): Specimen dimensions and (b): The final adaptive mesh

Table 4: Dimensionless stress intensity factors for double edge notched plate

\begin{tabular}{lll}
\hline$(\mathrm{a} / \mathrm{W})$ & Tada et al. $^{[22]}$ & Present study \\
\hline 0.1 & 1.1219 & 1.1196 \\
0.2 & 1.1237 & 1.1218 \\
0.3 & 1.1312 & 1.1260 \\
0.4 & 1.1491 & 1.1489 \\
0.5 & 1.1841 & 1.1829 \\
0.6 & 1.2471 & 1.2483 \\
0.7 & 1.3598 & 1.3560 \\
0.8 & 1.5772 & 1.5731 \\
0.9 & 2.1179 & 2.1113 \\
\hline
\end{tabular}

Double edge notched plate (DENT): The geometry of the double edge notched plat specimen and the final adaptive mesh for $(\mathrm{h} / \mathrm{W}=5 / 3)$ are shown in Fig. 5. The analytical solution of stress intensity factor for this specimen was given by Tada et al..$^{[22]}$ as:

$\mathrm{K}_{\mathrm{I}}=\frac{\sigma \sqrt{\pi \mathrm{a}}}{\sqrt{1-\frac{\mathrm{a}}{\mathrm{W}}}}\left[\begin{array}{c}1.122-0.561\left(\frac{\mathrm{a}}{\mathrm{W}}\right)-0.205\left(\frac{\mathrm{a}}{\mathrm{W}}\right)^{2} \\ +0.471\left(\frac{\mathrm{a}}{\mathrm{W}}\right)^{3}-0.190\left(\frac{\mathrm{a}}{\mathrm{W}}\right)^{4}\end{array}\right]$

The non-dimensional stress intensity factor, was given by Zhu and Smith ${ }^{[23]}$ as follows:

$\overline{\mathrm{K}}_{\mathrm{I}}=\mathrm{K}_{\mathrm{I}} /(\sigma \sqrt{\pi \mathrm{a}})$

The present results for various initial crack lengths shown in Table 4, exhibit close agreement to the analytical solutions calculated by Eq. 2 .

To show the accuracy of the SIF prediction, different initial crack length $\mathrm{a} / \mathrm{W}=0.8$ and 0.9 , for two plate geometries $\mathrm{h} / \mathrm{W}=1$ and 3 are also tested. Normalized stress intensity factors were calculated and compared to the analytical solution which was presented by ${ }^{[24]}$ using meshless methods as a comparison to the analytical solutions given by ${ }^{[25,26]}$ as illustrated in Table 5. As shown in this Table 5 the agreements are obviously excellent.

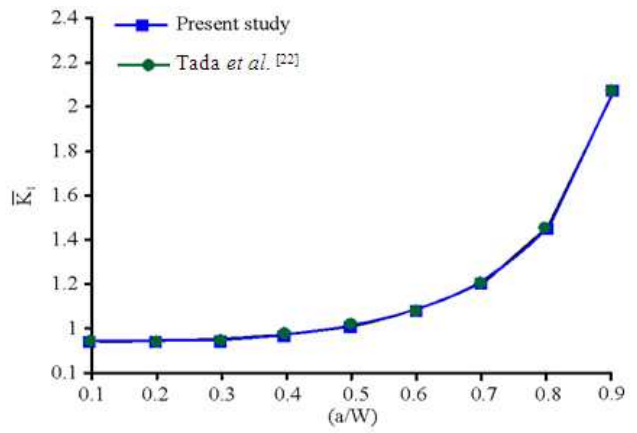

Fig. 6: Relationship between SIF and initial crack length size for the double edge notched plate

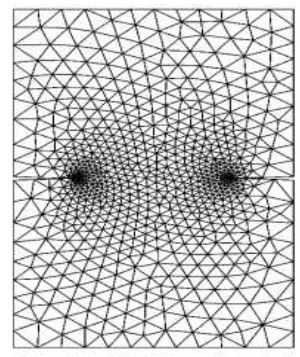

(1)

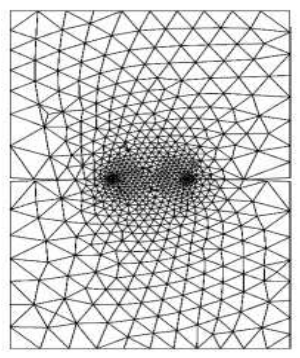

(3)

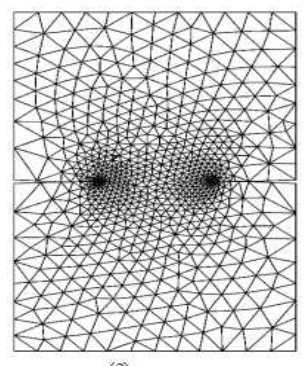

(2)

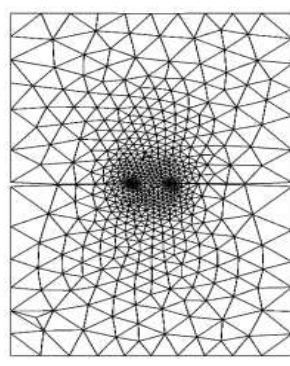

(4)
Fig. 7: The crack propagation trajectory for a double edge notched plate under mode I loading

Table 5: Normalized stress intensity factor for double edge notched plate

\begin{tabular}{llllll}
\hline$(\mathrm{a} / \mathrm{W})$ & $(\mathrm{h} / \mathrm{W})$ & $\begin{array}{l}\text { Muravin and } \\
\text { Turkel }^{[2]}\end{array}$ & $\begin{array}{l}\text { Beltschko } \text { et al. } \\
{[25]}\end{array}$ & $\begin{array}{l}\text { Lu } \text { et al. } \\
{[22]}\end{array}$ & $\begin{array}{l}\text { Present } \\
\text { study }\end{array}$ \\
\hline 0.8 & 1 & 1.6111 & 1.5806 & 1.6432 & 1.5995 \\
0.8 & 3 & 1.5497 & 1.5649 & --- & 1.5483 \\
0.9 & 1 & 2.1326 & 2.1133 & --- & 2.1277 \\
0.9 & 3 & 2.1016 & 2.1133 & --- & 2.1051 \\
\hline
\end{tabular}

Figure 6, represented the comparison between the present study results of the dimensionless SIF and the analytical solution obtained by Tada et al. ${ }^{[22]}$ which were listed in Table 3. As shown in this Figure 6 the SIF is increase nonlinearly as $(\mathrm{a} / \mathrm{W})$ increase.

Similarly, Fig. 7 shows, four steps of central crack propagation for $\mathrm{a} / \mathrm{W}=0.5$ and $(\mathrm{h} / \mathrm{W}=5 / 3)$. The crack 
propagates towards the expected path under mode I loading condition.

\section{CONCLUSION}

A developed source code program of comprehensive finite element model have been performed in this research work with an advancing front method for crack propagation analysis. The prediction of SIF for a crack emanating from circular hole in rectangular plate and double edge notched plate were considered under mode I loading, using an adaptive mesh finite element strategy. Based, on the obtained by current studies, it's seen that are very close with other compared results. In addition, this developed source program shows that is capable of demonstrating the SIF evaluation and the crack path direction satisfactorily. Finally, the numerical finite element analysis with displacement extrapolation method, have been successfully employed for linear-elastic fracture mechanics problems.

\section{REFERENCES}

1. Gustavo, V.G., P. Jaime and E. Manuel, 2000. KI evaluation by the displacement extrapolation technique. Eng. Fract. Mech., 66: 243-255. DOI: 10.1016/S0013-7944(00)00016-3

2. De Araújo, T., T. Bittencourt, D. Roehl and L. Martha, 2000. Numerical estimation of fracture parameters in elastic and elastic-plastic analysis. Proceeding of the European Congress on Computational Methods in Applied Sciences and Engineering, Sep. 11-14, Barcelona, pp: 1-18. http://www.tecgraf.pucrio.br/publications/artigo_2000_numerical_estimati on_fracture_parameters.pdf

3. Yan, X., 2006. Cracks emanating from circular hole or square hole in rectangular plate in tension. Eng. Fract. Mech., 73: 1743-1754. DOI: 10.1016/J.ENGFRACMECH.2006.02.003

4. Murakami, Y., 1978. A method of stress intensity factor calculation for the crack emanating from an arbitrarily shaped hole or the crack in the vicinity of an arbitrarily shaped hole. Trans Jap. Soc. Mech. Eng., 44: 423-32.

5. Shahani, A. and S. Tabatabaei, 2008. Computation of mixed mode stress intensity factors in a fourpoint bend specimen. Applied Math. Model., 32: 1281-1288. DOI: 10.1016/J.APM.2007.04.001

6. Laurencin, J., G. Delette and M. Dupeux, 2007. An estimation of ceramic fracture at singularities by a statistical approach. J. Eur. Ceramic Soc., 28: 1-13. http://cat.inist.fr/?aModele $=$ afficheN\&cpsidt $=1937$ 2889
7. Kutuka, M.A., N. Atmacab and I.H. Guzelbey, 2007. Explicit formulation of SIF using neural networks for opening mode of fracture. Int. J. Eng. Struct., 29: 2080-2086. DOI: 10.1016/J.ENGSTRUCT.2006.11.008

8. Aour, B., O. Rahmani and B. Nait-Abdelaziz, 2007. A coupled FEM/BEM approach and its accuracy for solving crack problems in fracture mechanics. Int. J. Solids Struct., 44: 2523-2539. http://cat.inist.fr/?aModele $=$ afficheN\&cpsidt $=1858$ 2833

9. Stanislav, S. and K. Zdenek, 2008. Two parameter fracture mechanics: Fatigue crack behavior under mixed mode conditions. Eng. Fract. Mech., 75: $857-865$.

DOI: 10.1016/J.ENGFRACMECH.2007.04.011

10. Owen, D., 1973. Stress intensity factors for cracks in a plate containing a hole and in a spinning disc. Int. J. Fract., 4: 471-476. DOI: 10.1007/BF00036327

11. Chang, R., 1981. Static finite element stress intensity factors for annular cracks. J. Nondestruct. Evaluat., 2: 119-124. DOI: 10.1007/BF00566309

12. Newman, J., 1971. An improved method of collocation for the stress analysis of cracked plates with various shaped boundaries. NASA TN., 6376: 1-45.

13. Bowie, O.L., 1956. Analysis of an infinite plate containing radial cracks originating at the boundary of an internal circular hole. J. Math. Phys., 35: 60-71.

14. Abdelaziz, Y., N. Abou-bekr and A. Hamouine, 2007. Numerical modeling of the crack tip singularity, Int. J. Mater. Sci., 2: 65-72.

15. Alshoaibi, A., M. Hadi and A. Ariffin, 2007. Twodimensional numerical estimation of stress intensity factors and crack propagation in linear elastic analysis. J. Struct. Durability Health Monit., 3: $15-28$.

http://techscience.com/paper.asp?jnl=sdhm\&issue $=$ v3n $1 \&$ no=02

16. Löhner, R., 1997. Automatic unstructured grid generators. Finite Element Anal. Des., 25: 111-134. http://portal.acm.org/citation.cfm?id=249287

17. Zienkiewicz, O., R. Taylor and J. Zhu, 2005. The Finite Element Method: Its Basis and Fundamental. 6th Edn., Baker and Taylor Books. Oxford, ISBN: 10: 0750663200 , pp: 752.

18. Alshoaibi, M. and A. Ariffin, 2006. Finite element simulation of stress intensity factors in elasticplastic crack growth. J. Zhejiang Univ. Sci. Int. J. Applied Phys. Eng., 7: 1336-1342. DOI: 10.1631/jzus.2006.A1336 
19. Souiyah, M., A. Alshoaibi, A. Muchtar and A. Ariffin, 2008. Finite element model for linear-elastic mixed mode loading using adaptive mesh strategy. J. Zhejiang Univ. Sci A., 9: 32-37. DOI: 10.1631/jzus.A072176

20. Matos, P.F.P., P.M. Moreira, A. Portela and P.M. Castro, 2004. Dual boundary element analysis of cracked plates: Post-processing implementation of the singularity subtraction technique. Comput. Struct., 82 : 1443-1449. DOI: 10.1016/J.COMPSTRUC.2004.03.040

21. Freese, C. and D. Tracey, 1976. The natural triangle versus collapsed quadrilateral for elastic crack analysis. Int. J. Fract., 12: 767-770. DOI: 10.1007/BF00037924

22. Tada, H., P.C. Paris and G.R. Irwin, 2000. The Stress Analysis of Cracks Handbook. 3rd Edn., ASME Press, New York, USA., ISBN: 10: 0791801535, pp: 696.

23. Zhu, W. and D. Smith, 1995. On the use of the displacement extrapolation to obtain crack tip singular stresses and stress intensity factor. Eng. Fract. Mech., 51: 391-400. DOI: 10.1016/00137944(94)00319-D
24. Muravin, B. and E. Turkel, 2006. Multiple cracks multiple crack weight for solution of multiple cracks by meshless numerical methods. Int. J. Numer. Methods Eng., 67: 1146-1159. http://cat.inist.fr/?aModele $=$ afficheN\&cpsidt $=1807$ 9366

25. Belytschko, T., Y.Y. Lu and L. Gu, 1994. Elementfree Galerkin methods. Int. J. Numer. Methods Eng., 37: 229-256.

http://cat.inist.fr/?aModele $=$ afficheN\&cpsidt $=3873$ 468

26. Lu, Y.Y., T. Belytschko and M. Tabbara,1995. Element-free Galerkin method for wave propagation and dynamic fracture. Comput. Methods Applied Mech. Eng., 126: 131-153. DOI: 10.1016/0045-7825(95)00804-A 